\title{
Measurement and clinical effect of grey matter pathology in multiple sclerosis
}

\author{
Jeroen J G Geurts, Massimiliano Calabrese, Elizabeth Fisher, Richard A Rudick
}

Lancet Neurol 2012; 11: 1082-92

Department of Anatomy and Neurosciences, Section of Clinical Neuroscience, VU University Medical Center, Amsterdam, Netherlands (Prof JJ G Geurts PhD); Department of Neurosciences, Multiple Sclerosis Centre of Veneto Region-First Neurology Clinic, University Hospital of Padova, Padova, Italy (M Calabrese MD); and Department of Biomedical Engineering, Lerner Research Institute (E Fisher PhD) and Mellen Center, Neurological Institute (Prof R A Rudick MD), Cleveland Clinic, $\mathrm{OH}$, USA

Correspondence to: Prof Jeroen J G Geurts,

Department of Anatomy and Neurosciences, Section of Clinical Neuroscience, Van der Boechorststraat 7,

1081 BT Amsterdam, Netherlands j.geurts@vumc.nl

During the past 10 years, the intense involvement of the grey matter of the CNS in the pathology of multiple sclerosis has become evident. On gross inspection, demyelination in the grey matter is rather inconspicuous, and lesions in the grey matter are mostly undetectable with traditional MRI sequences. However, the results of immunohistochemical studies have shown extensive involvement of grey matter, and researchers have developed and applied new MRI acquisition methods as a result. Imaging techniques specifically developed to visualise grey matter lesions indicate early involvement, and image analysis techniques designed to measure the volume of grey matter show progressive loss. Together, these techniques have shown that grey matter pathology is associated with neurological and neuropsychological disability, and the strength of this association exceeds that related to white matter lesions or whole brain atrophy. By focusing on the latest insights into the in-vivo measurement of grey matter lesions and atrophy, we can assess their clinical effects.

\section{Introduction}

Multiple sclerosis has long been regarded as a typical white matter disease, with a primary autoimmune response directed against myelin components, resulting in focal inflammatory demyelination throughout the white matter. However, the involvement of the grey matter has become increasingly clear. As is the case in white matter, axons in the grey matter are myelinated, and demyelination of axons in grey matter regions has been seen on post-mortem examination of patients with multiple sclerosis since the beginning of the twentieth century. ${ }^{1,2}$ However, following those early studies, this finding was mainly disregarded for many years. In a seminal report published in 1962, Brownell and Hughes described 1594 lesions from 22 selected patients with multiple sclerosis, and reported that $26 \%$ of the demyelinated brain lesions were located within, or partly within, the cortex. ${ }^{3}$ Of the $26 \%$ grey matter-associated lesions, $17 \%$ were located at the junction of the cortex and the subcortical white matter. These numbers were probably an underestimation of the actual number of lesions present in the grey matter of patients with progressive multiple sclerosis (as defined in pathological studies $^{4,5}$ based on retrospective chart analysis). Conventional histochemical stains, such as Luxol Fast Blue (also known as Klüver-Barrera), that detect myelin lipids miss most of the superficially located cortical lesions, which are the most frequent cortical lesion type in multiple sclerosis. ${ }^{5}$ These subpial cortical, or type III, lesions were shown on later investigation with more modern myelin immunohistochemical stains to be extensive, and many involved several neighbouring gyri. ${ }^{5}$ Other, less frequent, types of cortical lesion are type II (small, perivascular) and type IV (large, cortexspanning). ${ }^{6}$ Type II and IV lesions are also best detected by myelin immunohistochemistry. Mixed white matter and grey matter, or type I, lesions are far less common in multiple sclerosis, although they can be detected with standard Luxol Fast Blue stains, which probably explains the high number of mixed lesions reported in the 1962 study. The different cortical lesion types as described in this Review have been defined by Bö and colleagues (figure 1$){ }^{6}$

\section{Demyelination of grey matter structures}

The use of myelin immunohistochemistry has greatly increased our knowledge about the prevalence and spatiotemporal patterns of grey matter lesions in multiple sclerosis (figure 2). ${ }^{7}$ In 2005, Kutzelnigg and colleagues described in detail the post-mortem findings on 51 patients with multiple sclerosis and compared the extent and localisation of grey and white matter pathology in different disease stages (defined according to Lublin and Reingold's criteria' by a retrospective medical chart analysis). The investigators reported that the acute and relapsingremitting phases were mainly characterised by focal, inflammatory demyelinated plaques in the periventricular white matter, whereas cortical demyelination and diffuse white matter inflammation were more characteristic of the primary progressive and secondary progressive disease stages. ${ }^{4}$ Several other groups studying postmortem material from patients with progressive multiple sclerosis (similarly assessed retrospectively) reported that demyelination can be found in many, if not all, grey matter areas, and the total extent of demyelination in the grey matter probably exceeds that in the white matter, especially in the secondary progressive disease phase. ${ }^{5,10}$ Gilmore and colleagues, ${ }^{10}$ who were studying autopsy material mostly from patients with progressive multiple sclerosis, reported that "overall $28.8 \%$ of the grey matter was demyelinated as compared with only $15 \cdot 6 \%$ of the white matter". This and other similar studies also showed that cortical and deep grey matter areas-motor cortex, frontal, temporal and parietal cortex, cingulate gyrus, cerebellum, thalamus, caudate, putamen, globus pallidus, claustrum, hypothalamus, hippocampus, substantia nigra, amygdala, and spinal cord grey matter-all showed extensive demyelination. ${ }^{4,10-15}$ The spinal cord showed especially prominent demyelination of grey matter, ${ }^{10,15}$ as did several neocortical areas, such as the cingulate gyrus., ${ }^{5,10}$ The 
hippocampus is one of the non-neocortical regions that is heavily affected by demyelination in the progressive disease phase. ${ }^{13,16}$ In one post-mortem study, 15 of 19 investigated patients with progressive multiple sclerosis had extensive demyelination of the hippocampus. ${ }^{13}$ Another study provided a detailed quantitative analysis of hippocampal autopsy tissue from 45 patients with progressive multiple sclerosis: ${ }^{16}$ Papadopoulos and coauthors identified 41 lesions in 28 of the 45 hippocampal multiple sclerosis blocks examined; the proportional area of demyelination averaged about $30 \% .{ }^{16}$ In both studies, most of the lesions were chronic, with a few foci of activated microglia present, mainly in areas that still contained myelin. Demyelination was generally not seen in the cornu ammonis (CA) 2 region of the hippocampus, ${ }^{13}$ and neuronal numbers were decreased by $30 \%$ in CA2 and CA3, and by $27 \%$ in CA1. Furthermore, in CA1, the size of neurons was reduced. ${ }^{16}$ Thus, gross hippocampal atrophy with a $22 \%$ reduction of the average crosssectional area of the hippocampus was reported, ${ }^{16}$ although other investigators could not confirm this result in later studies. ${ }^{17}$ In patients with progressive multiple sclerosis, Dutta and colleagues reported minimal neuronal loss in the hippocampus, but substantial decreases in synaptic density. ${ }^{17}$ They also reported lower than normal concentrations of mRNA and protein transcripts of fast axonal transport genes in demyelinated hippocampal neurons: concentrations of mRNA encoding kinesin and dynein proteins (which enable fast anterograde and retrograde axonal transport) were substantially lower than normal in microarray and quantitative RT-PCR analyses. Furthermore, concentrations of protein and mRNA for synaptic neurexin-neuroligin (which maintain synapticpostsynaptic contacts) were low, and clear indicators of disrupted glutamatergic neurotransmission (decreased ionotropic [AMPA/NMDA] and metabotropic glutamate receptors, their mRNA, or both) and disrupted glutamate homoeostasis (low concentrations of mRNA or protein of astrocytic glutamate transporters and glutamine synthase) were detected. Concentrations of activated calciumcalmodulin-dependent protein kinases (CaMK-II) and cyclic AMP response element-binding protein, two molecules involved in memory and learning, were substantially reduced in demyelinated hippocampi. ${ }^{17}$ These findings are important leads for understanding the memory disturbances seen in patients with multiple sclerosis. ${ }^{18}$

The cerebellar cortex is another non-neocortical grey matter area that is profoundly affected by demyelination. ${ }^{12}$ On average, $39 \%$ of the total cerebellar cortical area was demyelinated in patients with progressive (in most cases) multiple sclerosis, although extreme cases of up to $92 \%$ demyelination have been reported. Cerebellar cortical lesions mainly appeared in a band-like pattern, affecting multiple folia. The lesions are generally characterised by primary demyelination with relative neuroaxonal preservation, although some axonal spheroids and a

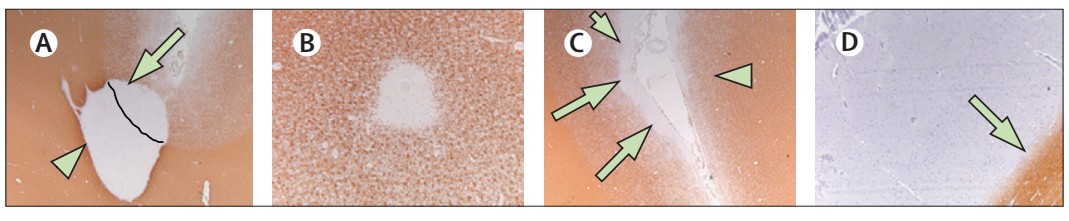

Figure 1: Pathological classification system of grey matter lesions in multiple sclerosis

(A) Type I lesions extend through both white matter and grey matter. The arrowhead indicates the white matter portion of the mixed white matter-grey matter lesion. The arrow points toward the grey matter part of that same lesion. The black line indicates the border between grey and white matter, showing that type I lesions cross this border. (B) Type II lesions are located entirely within the cortex, without touching the subcortical white matter or the pial surface of the brain. (C) Type III lesions extend inward from the pial surface and stop before they reach the border of white matter and grey matter. The arrows indicate a type III subpial cortical lesion. The arrowhead indicates normally myelinated (adjacent) grey matter. (D) Type IV lesions cover the entire width of the cortex, without extending into the subcortical white matter. The arrow indicates the border of the grey matter and white matter, as well as the border of the grey matter type IV lesion. This type of lesion typically respects the grey matterwhite matter border. Adapted from Geurts and Barkhof, ${ }^{7}$ by permission of Elsevier.

moderate reduction of Purkinje cells can be present. Although cerebellar cortical demyelination sometimes occurs with demyelination in the adjacent white matter, the cortex is usually affected independently from cerebellar white matter lesions. ${ }^{12}$ The main band-like demyelination pattern and the relative cellular preservation in the cerebellar cortex are consistent with findings within the cerebral cortex in the progressive phase of the disease. ${ }^{4,5,19,20}$ In several post-mortem studies of patients with progressive multiple sclerosis, ${ }^{21,22}$ neurochemical abnormalities and neurodegenerative processes (ie, axonal, neuronal, or synaptic damage) were found independently of local grey matter demyelination. Thus, although more work is clearly needed, an important issue is whether neurodegeneration and demyelination might become partly independent at some point in the disease.

Although the described studies have elicited new and important insights about the topology and extent of neuropathological changes in multiple sclerosis, methodological differences between research groups, and largely non-systematic, non-random sampling, from patients with disease at different stages, restricts the comparability of post-mortem studies. Careful efforts to standardise tissue sampling and processing across centres, and systematic comparisons of pathological changes in early and progressive disease stages, are now needed.

\section{The debate about grey matter pathogenesis}

What exactly causes grey matter pathology in multiple sclerosis remains unclear, although several hypotheses have been proposed (figure 3). The full complexity of the debate is beyond the scope of this Review, but some recent discoveries that provide a background for subsequent sections on the visualisation of grey matter damage in vivo are discussed.

\section{Grey matter demyelination}

One of the main theories about the pathogenesis of grey matter lesions is based on the suggestion that meningeal inflammation and associated myelinotoxic agents that might be produced in the meninges and then diffuse into 


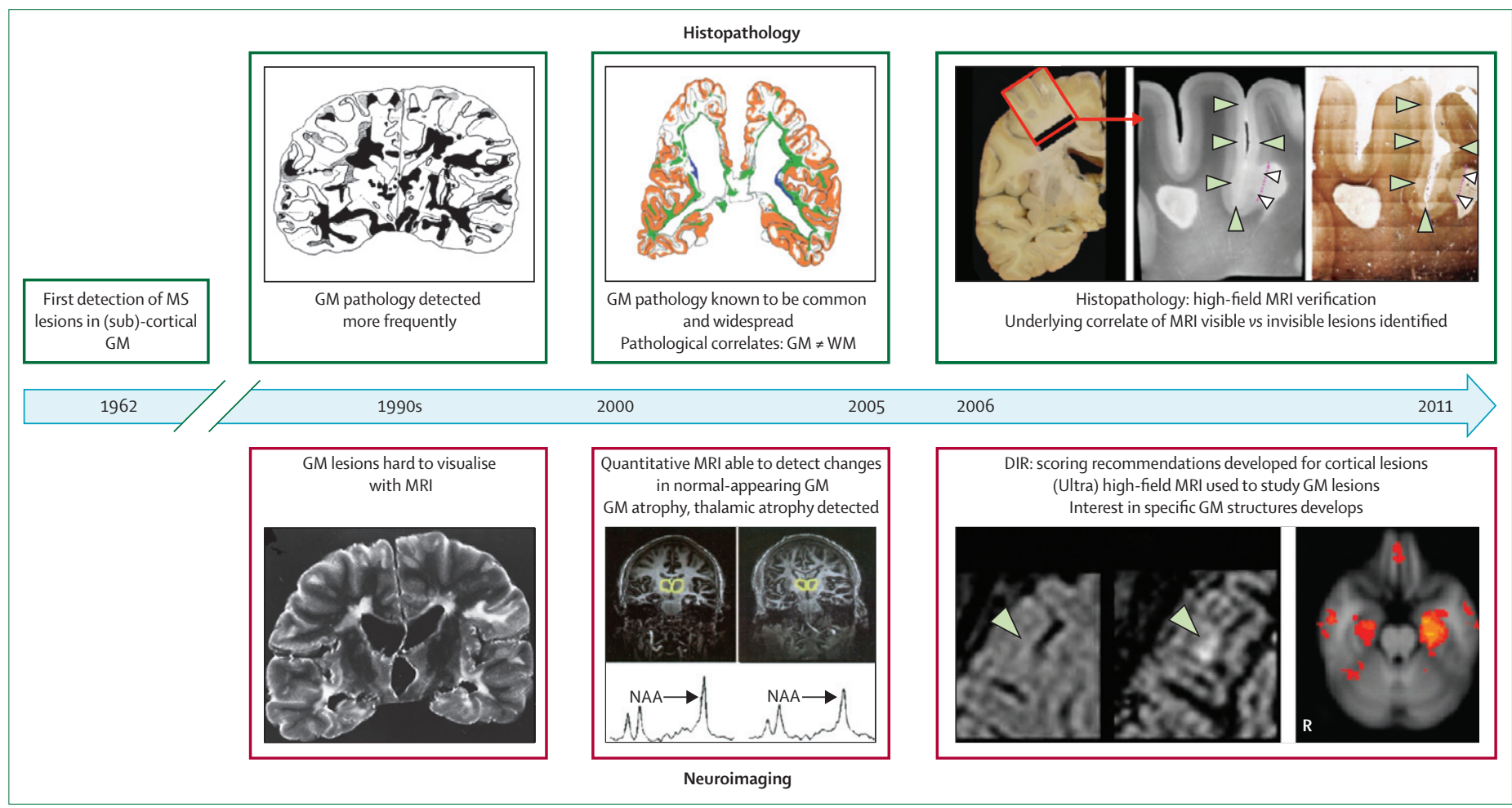

Figure 2: Timeline of developments in grey matter imaging and pathology in multiple sclerosis

$\mathrm{MS}=$ multiple sclerosis. $\mathrm{GM}=$ grey matter. $\mathrm{WM}=$ white matter. $\mathrm{NAA}=\mathrm{N}$-acetyl aspartate. $\mathrm{DIR}=$ double inversion recovery. Adapted with permission from Hulst and Geurts. ${ }^{8}$

the cortex could be causally related to cortical demyelination, especially to the band-like subpial lesions. Several autopsy studies have shown that meningeal inflammation is present in multiple sclerosis, ${ }^{4,23-25}$ in some cases associated with the formation of ectopic B-cell follicles that might or might not be positive for the Epstein-Barr virus. ${ }^{26-29}$ However, meningeal infiltrates were not always related to underlying cortical demyelination. ${ }^{25}$ Consistent findings on grey matter lesions in autopsy studies are: a notable absence of cellular infiltration, blood-brain barrier leakage, and complement deposition in cortical lesions from the brains of patients with long-standing multiple sclerosis. ${ }^{4,6,30,31}$ These findings contrast with results from biopsy studies of acute demyelinating pathologies that later mostly developed into multiple sclerosis, which showed that early cortical pathology can be substantially inflammatory. ${ }^{32,33}$ Whether inflammation is a prerequisite for the development of cortical lesions cannot yet be definitively concluded. Both autopsy and biopsy studies are affected by substantial biases. The acute biopsy cases might be atypical simply because their overall inflammatory profiles are extraordinary (which necessitated the biopsy in the first place). Autopsy studies generally use material from patients with progressive multiple sclerosis, in which inflammation in the cortex could have already subsided. Future research should define and describe in detail the different phases of cortical lesion formation in multiple sclerosis and show whether different phases of grey matter lesions can be detected in all stages of the disease, as is the case for white matter lesions.

\section{Grey matter tissue degeneration}

Tissue degenerative processes in multiple sclerosis do not necessarily coincide with demyelination: white matter and grey matter pathology might be at least partly independent in progressive multiple sclerosis. ${ }^{4,21,22}$ In-vivo grey matter atrophy measures might therefore reflect combinations of demyelination, neurite transection, ${ }^{19}$ and reduced synapse or glial densities. ${ }^{17,21}$ Several disease mechanisms have been proposed in association with tissue degeneration in the cortex. Mitochondrial dysfunction is one of the mechanisms that have received much attention. Irrespective of the presence of grey matter lesions, neurons with deficiencies in the respiratory chain have been discovered in the cortex of patients with multiple sclerosis. ${ }^{34}$ These neurons have many clonally expanded mitochondrial DNA deletions at the single-cell level and lack mitochondrial DNA-encoded catalytic subunits of complex IV of the respiratory chain. Concentrations of neuronal proteins essential for axonal transport, synaptic plasticity, and glutamate neurotransmission and homoeostasis were also substantially lower than normal in the grey matter of multiple sclerosis patients. ${ }^{17,35}$ Abnormalities in ion channels could be another possible mechanism; Srivastava and colleagues showed that potassium channel KIR4.1 
could be a target of an autoantibody response in a subgroup of patients with multiple sclerosis. ${ }^{36}$ Excessive stimulation of calcium-dependent pathways, leading to neurodegeneration, could be triggered by the deleterious combination of mitochondrial dysfunction (due to defective oxidative phosphorylation or nitric oxide production), influx of sodium ions through voltage-gated channels, release of toxic calcium ions from the axoplasmic reticulum, overactivation of ionotropic and metabotropic axonal glutamate receptors in combination with downregulation of glutamate transporters in the cortex of patients with multiple sclerosis, and activation of voltagegated calcium channels. ${ }^{37}$

How, and to what extent, these disease mechanisms control the complex pathological interplay in multiple sclerosis is not yet clear. Nor is it yet obvious how inflammatory demyelination in white matter and grey matter is related to neurodegeneration. Several hypotheses about grey matter pathogenesis and the relation between neurodegeneration and neuroinflammation are being investigated, ${ }^{38,39}$ and future studies of well-characterised post-mortem tissue and advanced, pathology-specific imaging techniques should clarify this issue further.

\section{Imaging of grey matter demyelination and degeneration}

In-vivo imaging could help to address questions about the spatiotemporal development of grey matter pathology in multiple sclerosis. Modern neuroimaging techniques can be used to optimally measure grey matter lesions and grey matter atrophy as signs of continuing demyelination and neurodegeneration. These measurements can also be used to elucidate clinical disability and cognitive impairment in multiple sclerosis.

\section{Visualisation of grey matter lesions}

Although the first accurate histological reports of demyelinated foci in the cortex of multiple sclerosis patients date back to the beginning of the twentieth century, visualisation of grey matter lesions in vivo has been difficult because of the limitations of conventional MRI techniques. With the introduction of a more sensitive MRI acquisition technique, double inversion recovery (figure 4), ${ }^{41,42}$ five times more grey matter cortical lesions could be detected than with a conventional T2-weighted sequence. ${ }^{42}$ However, about $80 \%$ of grey matter lesions observed by microscopy are missed with double inversion recovery. ${ }^{43}$ In particular, subpial cortical lesions remain largely undetected. ${ }^{43-45} \mathrm{~A}$ disadvantage of double inversion recovery is its low signal-to-noise ratio, which results in low agreement between observers. ${ }^{40}$ International guidelines have been proposed to facilitate scoring of cortical grey matter lesions on double inversion recovery images; ${ }^{40}$ they will need to be updated when the double inversion recovery technique is standardised between research centres.

Double inversion recovery has been combined with

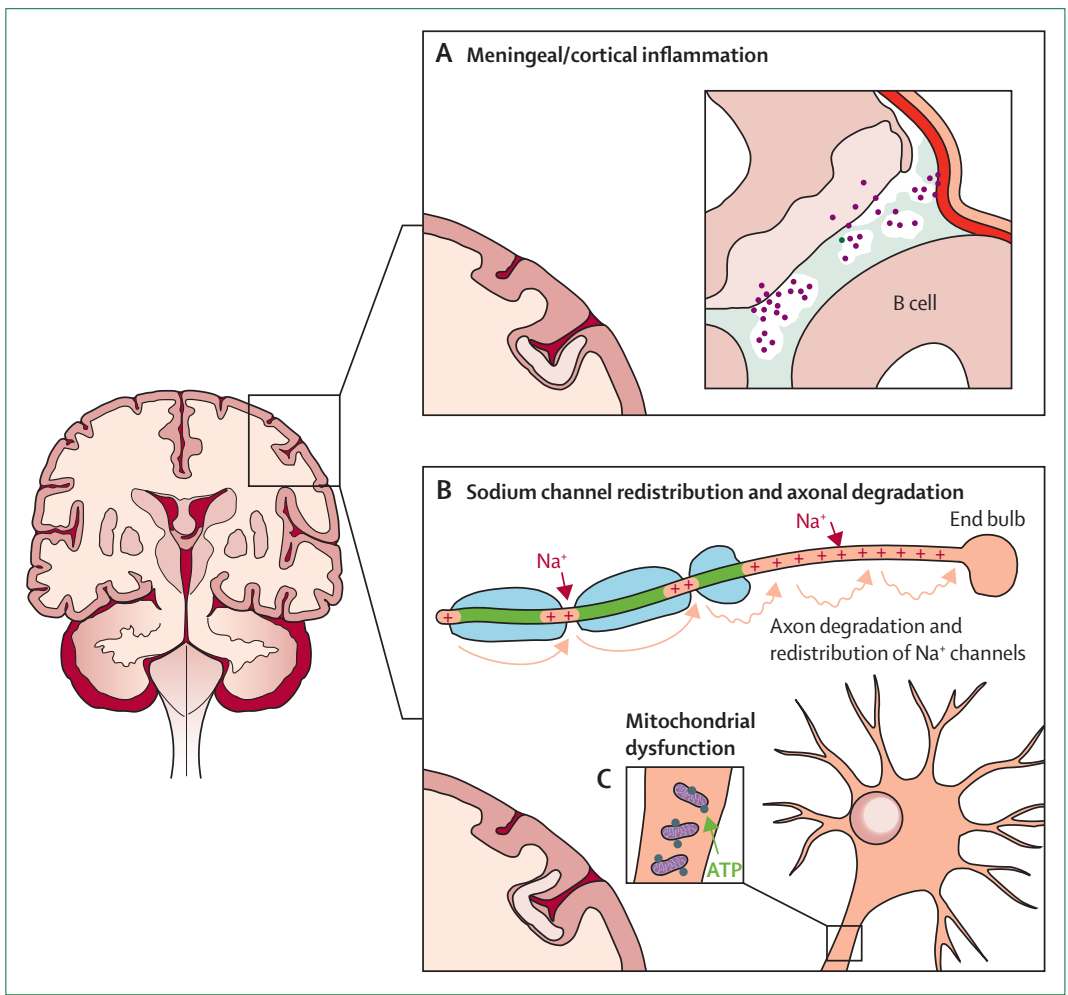

Figure 3: Three pathogenic mechanisms thought to be involved in grey matter pathology Several pathogenic mechanisms have been suggested as causal factors in the development of grey matter pathology in multiple sclerosis. Meningeal inflammation (A) has been related to cortical demyelination, and patients with early, very active, multiple sclerosis might even show inflammation in the cortex. Pathology originating in the white matter can also affect the grey matter. The combination of a redistribution of sodium channels over the length of axons upon axonal demyelination (B) and mitochondrial abnormalities in axons (C) could generate a dysbalance in cellular energy demand and supply, leading to dying back axonopathy, and ultimately atrophy of the cortical grey matter.

other sequences, such as phase-sensitive inversion recovery ${ }^{46}$ and T1-weighted three-dimensional spoiled gradient-recalled echo, ${ }^{47}$ but imaging of grey matter lesions at standard clinical field strength is suboptimal. Ultra-high-field MRI (ie, $\geq 7 \mathrm{~T}$ ), which is not yet widely available, has substantially improved detection of cortical lesions, especially subpial cortical lesions, both ex vivo

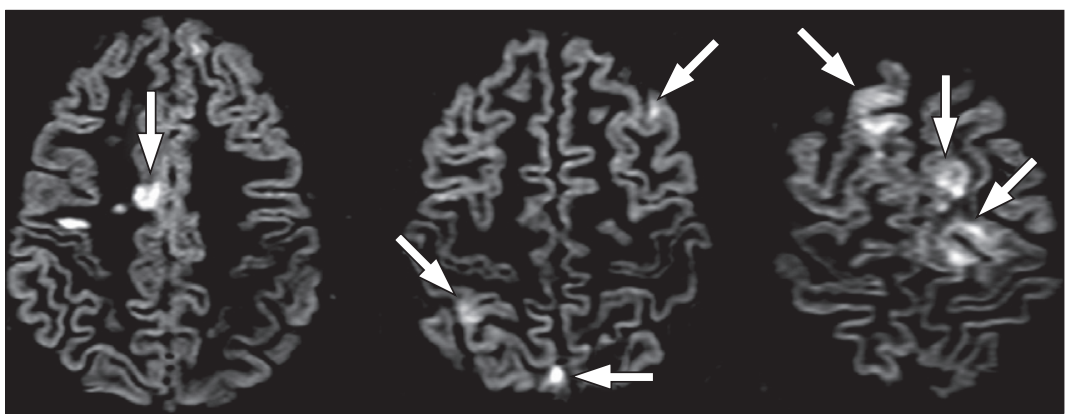

Figure 4: Cortical lesions on double inversion recovery MRI

Three axial double inversion recovery images of a 32-year-old patient with relapsing-remitting multiple sclerosis. Several intracortical lesions and mixed grey matter and white matter lesions are shown (arrows), together with typical multiple sclerosis white matter lesions. Common areas prone to artifacts on double inversion recovery have been described..$^{40}$ 
and in vivo. ${ }^{48,49}$ Of 36 histologically detected cortical lesions, 28 (77\%) were identified retrospectively by ultrahigh-field MRI. ${ }^{49}$

Why some cortical lesions are visible on magnetic resonance images and others are not is unknown. A comparative post-mortem MRI and histopathology study has shown that MRI-visible cortical lesions do not differ from MRI-invisible lesions in terms of their pathological profiles (inflammation, gliosis, etc) ${ }^{45}$ rather, MRI visibility of cortical lesions depends on the size of the lesions. Large lesions, involving several cortical layers and potentially multiple gyri, show up more readily; so what is visible on MRI could be only the tip of the pathological iceberg. However, because MRI-visible cortical lesions are strongly associated with the MRI-invisible lesions ${ }^{45}$ visualisation of the tip of the iceberg could be sufficient to obtain a preliminary idea of the extent of grey matter demyelination, at least until new techniques are available and detection of grey matter lesions improves further.

\section{Clinical relevance of grey matter lesions Diagnostic implications}

In-vivo studies (table 1) show that grey matter lesions occur frequently and early in all multiple sclerosis phenotypes, including patients who present with clinically isolated syndromes ${ }^{50}$ or even radiologically

\begin{tabular}{|c|c|c|c|}
\hline & Method & $\mathbf{N}$ & Main findings \\
\hline $\begin{array}{l}\text { Calabrese } \\
\text { et al, } 2007^{50}\end{array}$ & $1.5 \mathrm{~T} ; \mathrm{DIR}$ & $\begin{array}{l}380 \text { MS, } \\
40 \text { controls }\end{array}$ & $\begin{array}{l}\text { The number of cortical lesions correlated with the EDSS } \\
\text { score }(r=0.48, p=0.001)\end{array}$ \\
\hline $\begin{array}{l}\text { Calabrese } \\
\text { et al, } 2009^{51}\end{array}$ & 1.5T; DIR & $\begin{array}{l}48 \text { benign, } \\
96 \text { relapsing- } \\
\text { remitting MS }\end{array}$ & $\begin{array}{l}\text { Low number of cortical lesions and low cortical lesion } \\
\text { volume associated with benign course of the disease } \\
\text { (low disability } 15 \text { years after disease onset) }\end{array}$ \\
\hline $\begin{array}{l}\text { Roosendaal } \\
\text { et al, } 2009^{52}\end{array}$ & 1.5T; DIR & $13 \mathrm{MS}$ & $\begin{array}{l}\text { Cortical lesions increase substantially over } 3 \text { years, are } \\
\text { most frequent in patients with secondary progressive } \\
\text { MS, and are associated with cognitive impairment }\end{array}$ \\
\hline $\begin{array}{l}\text { Calabrese } \\
\text { et al, } 2009^{53}\end{array}$ & $1.5 \mathrm{~T} ; \mathrm{DIR}$ & $70 \mathrm{MS}$ & $\begin{array}{l}\text { Cortical lesion volume correlated with cognitive } \\
\text { impairment index and with almost all cognitive tests of } \\
\text { Rao's brief repeatable battery }\end{array}$ \\
\hline $\begin{array}{l}\text { Calabrese } \\
\text { et al, } 2009^{54}\end{array}$ & $1.5 \mathrm{~T} ; \mathrm{DIR}$ & $\begin{array}{l}48 \text { primary } \\
\text { progressive } \\
\text { MS }\end{array}$ & $\begin{array}{l}\text { Cortical lesion volume at baseline was the best predictor } \\
\text { of percentage change in grey matter volume and } \\
\text { disability accumulation during the subsequent } 2 \text { years }\end{array}$ \\
\hline $\begin{array}{l}\text { Calabrese } \\
\text { et al, 2010 }\end{array}$ & 1.5T; DIR & $107 \mathrm{MS}$ & $\begin{array}{l}\text { Cortical lesion volume correlated with baseline EDSS and } \\
\text { is the best predictor of EDSS accumulation over } 3 \text { years in } \\
\text { relapsing-remitting and secondary progressive MS }\end{array}$ \\
\hline $\begin{array}{l}\text { Bagnato et al, } \\
2010^{56}\end{array}$ & 3T; IRSPGR & $\begin{array}{l}21 \mathrm{MS} \\
21 \text { controls }\end{array}$ & $\begin{array}{l}\text { Cortical lesions affect cognitive impairment, not } \\
\text { independently from white matter disease }\end{array}$ \\
\hline $\begin{array}{l}\text { Mike et al, } \\
2011^{57}\end{array}$ & 3D IRSPGR & $26 \mathrm{MS}$ & $\begin{array}{l}\text { Cortical lesion number and volume correlated with } \\
\text { SDMT and EDSS; number correlated with CVLT-II scores }\end{array}$ \\
\hline $\begin{array}{l}\text { Nelson et al, } \\
2011^{58}\end{array}$ & 3T; DIR/PSIR & 39 MS & $\begin{array}{l}\text { Cortical lesions have an important role in cognitive } \\
\text { impairment. The size of the cortical lesion, and not the } \\
\text { tissue-specific location, may best explain their } \\
\text { correlation with cognitive impairment }\end{array}$ \\
\hline $\begin{array}{l}\text { Nielsen et al, } \\
2011^{59}\end{array}$ & $\begin{array}{l}7 \mathrm{~T} ; \mathrm{T}^{*}-2 \mathrm{D} \\
\text { FLASH }\end{array}$ & $17 \mathrm{MS}$ & $\begin{array}{l}\text { Subpial cortical lesions better detected with FLASH-T2* } \\
\text { at } 7 \text { T than with DIR at } 3 T\end{array}$ \\
\hline \multicolumn{4}{|c|}{$\begin{array}{l}\text { DIR=double inversion recovery. MS=multiple sclerosis. EDSS=expanded disability status scale. SDMT=symbol digit } \\
\text { modality test. CVLT-II=California verbal learning test, second edition. IRSPGR=inversion-recovery spoiled } \\
\text { gradient- recalled echo. PSIR=phase-sensitive inversion recovery. FLASH=fast low angle shot. }\end{array}$} \\
\hline
\end{tabular}

isolated syndrome. ${ }^{60}$ In some cases, grey matter lesions even precede the appearance of white matter lesions, ${ }^{33,61,62}$ which is in line with histological reports of patients with early relapsing-remitting disease. ${ }^{32,33}$ Although more work is needed, this observation could be of great clinical relevance. In a 4-year longitudinal study, ${ }^{63}$ the predictive role of cortical lesions in patients with clinically isolated syndromes was compared with the available diagnostic criteria, which are primarily based on white matter involvement. ${ }^{64,65}$ In that study, the presence of at least one cortical lesion was associated with a higher risk of conversion to definite multiple sclerosis within a short period; if this finding is confirmed in further longitudinal, multicentre studies, inclusion of cortical lesions in the diagnostic criteria of multiple sclerosis would be highly beneficial.

\section{Prognostic implications}

Despite the limitations in the identification of grey matter lesions in vivo, preliminary reports have provided convincing evidence of an association between grey matter lesions and physical disability. A moderate correlation between clinical disability and cortical lesion burden has been reported in all multiple sclerosis phenotypes. ${ }^{50}$ A 3-year longitudinal study showed that cortical lesion number and lesion volume increased significantly more quickly over time in patients who worsened clinically than in those who remained clinically stable. ${ }^{55}$ Cortical lesion volume and white matter lesion volume at study entry were independent predictors of disability progression over the next 3 years, which implies that cortical lesions might be a useful paraclinical tool to assess disease evolution, in addition to white matter lesion load. ${ }^{55}$

These preliminary results are similar to observations in patients with primary progressive multiple sclerosis, as defined by the Thompson criteria, ${ }^{66}$ in whom cortical lesions have been observed in up to $80 \%$ of individuals. Cortical lesions were significantly correlated with EDSS at baseline and disability progression at follow-up, whereas a multivariate analysis identified cortical lesion volume as the best predictor of disability increase over the next 2 years. ${ }^{54}$

By contrast, patients with benign multiple sclerosis (ie, EDSS $\leq 3.0$ after 15 years from clinical onset) showed significantly lower cortical lesion numbers, lower cortical lesion volumes, and slower accumulation of cortical lesions than patients with early relapsing-remitting multiple sclerosis who had a similar degree of disability but shorter disease duration. In multivariate analysis, cortical lesion volume and volume increase over time were the best predictors of a benign disease course. ${ }^{51}$ Together, these observations indicate that cortical damage in multiple sclerosis is related to an unfavourable clinical course.

Cortical pathology could substantially affect not only clinical disability but also cognitive dysfunction in multiple sclerosis. The overall burden of white matter 
lesions does not fully account for the severity of cognitive impairment in multiple sclerosis. ${ }^{67,68}$ Indeed, cortical ${ }^{52}$ and hippocampal ${ }^{69}$ lesion counts were significantly associated with impairment of visuospatial memory and processing speed, and cortical lesion volume was related to overall cognitive impairment. ${ }^{53}$ Finally, in addition to the number of grey matter lesions, the size of lesions was also relevant to cognitive deterioration..$^{58}$

\section{Cortical grey matter lesions in clinical trials}

No definitive consensus exists about how best to measure cortical grey matter lesions with MRI, and MRI techniques, or combinations of MRI techniques, still produce suboptimal results. Double inversion recovery, for example, could be the most suitable candidate for inclusion in clinical trials, but acquisition with this method has not been standardised across centres. Despite the proposal of international consensus criteria for scoring of cortical grey matter lesions, agreement between raters using different double inversion recovery sequences is still suboptimal. ${ }^{40}$ Therefore, until these sequences are standardised between centres, the use of double inversion recovery to quantify cortical lesions is useful within, but not between, centres of expertise. By inference, double inversion recovery (or other contrasts for cortical lesion visualisation) could be very useful in assessment of cortical damage in relation to cognitive impairment in individual patients. ${ }^{61,62}$ However, to monitor overall grey matter damage in multicentre clinical trials, measures of grey matter atrophy might be more feasible than measures of cortical lesions at this point. ${ }^{70}$

\section{Grey matter atrophy}

Measurement of grey matter atrophy with MRI

Several studies have documented progressive loss of brain parenchyma, starting at the clinically isolated syndrome stage and continuing throughout the long course of the disease. ${ }^{71-74}$ Grey matter constitutes about $65 \%$ of brain parenchymal tissue, and atrophy of grey matter largely drives whole brain atrophy in multiple sclerosis. ${ }^{75,76}$ Decreased grey matter volume is the end result of pathological processes that affect both grey and white matter in multiple sclerosis. Indeed, grey matter volume measures are inherently non-specific; they reveal nothing about the exact cause of the tissue injury. However, in view of the extensive grey matter pathology in multiple sclerosis, studies of grey matter atrophy are particularly interesting because: grey matter lesions are difficult to visualise, even with specialised MR sequences; grey matter atrophy measurements can be done with conventional MRI and available software; and grey matter atrophy is more strongly associated with neurological disability than are other imaging metrics.

Investigators can use several methods to quantify grey matter loss. The most common approach is to use image analysis software to segment total grey matter (cortical and deep grey matter), ${ }^{7-81}$ cortical grey matter only, ${ }^{81}$ or specific structures, such as the thalamus or hippocampus. ${ }^{82,83}$ Total grey matter volume can be quantified and expressed as an absolute volume, a normalised absolute volume calculated by transformation to standard space, or as a normalised fraction of the intracranial volume. Investigators can use widely available, general-use brain segmentation software packages ${ }^{78,81,84}$ to estimate grey matter atrophy in patients with multiple sclerosis (eg, see several examples in the FSL library ${ }^{85}$ ). Importantly, the signal intensity of multiple sclerosis white matter lesions can resemble the signal intensity of normal-appearing grey matter, which complicates brain tissue classification and can lead to inaccurate results. ${ }^{7,82-84}$ If the lesions are not accounted for during analysis, up to $50 \%$ of voxels within lesions could be erroneously classified as grey matter. ${ }^{86}$

Another approach is to estimate changes in cortical thickness. Cortical thinning can be measured in individual patients over time by use of cortical deformation modelling software to estimate changes in mean cortical thickness, either over the whole brain or over individual regions..$^{87,88}$ Cortical thinning can also be studied through comparisons between groups of patients by voxel-based morphometry. ${ }^{78}$ Both methods have been used in multiple sclerosis studies.

\begin{tabular}{|c|c|c|c|}
\hline & Method & $\mathbf{N}$ & Main findings \\
\hline $\begin{array}{l}\text { De Stefano et al, } \\
2003^{95}\end{array}$ & NCV & $90 \mathrm{MS}$ & $\begin{array}{l}\text { NCV correlated with EDSS; correlations with EDSS stronger } \\
\text { in primary progressive than in relapsing-remitting MS; low } \\
\text { NCV even in patients with MS for }<5 \text { years and in patients } \\
\text { with low lesion loads }\end{array}$ \\
\hline $\begin{array}{l}\text { Amato et al, } \\
2004^{99}\end{array}$ & NCV & $\begin{array}{l}41 \mathrm{MS}, \\
16 \text { controls }\end{array}$ & $\begin{array}{l}\text { NCV lower in cognitively impaired MS patients; NCV } \\
\text { correlated with neuropsychological tests of verbal memory, } \\
\text { verbal fluency, and attention/concentration }\end{array}$ \\
\hline $\begin{array}{l}\text { Tedeschi et al, } \\
2005^{100}\end{array}$ & GMF & $\begin{array}{l}595 \text { MS, } \\
104 \text { controls }\end{array}$ & GMF was the only MRI measure that correlated with EDSS \\
\hline $\begin{array}{l}\text { Sanfilipo et al, } \\
2005^{101}\end{array}$ & GMF & $\begin{array}{l}41 \mathrm{MS}, \\
18 \text { controls }\end{array}$ & $\begin{array}{l}\text { GMF was the only significant predictor of EDSS and } 25 \text {-feet } \\
\text { timed walk }\end{array}$ \\
\hline $\begin{array}{l}\text { Fisniku et al, } \\
2008^{102}\end{array}$ & GMF & $\begin{array}{l}44 \mathrm{MS}, 29 \mathrm{CIS} \\
25 \text { controls }\end{array}$ & $\begin{array}{l}\text { GMF was strongest MRI predictor of EDSS and only MRI } \\
\text { predictor of MSFC }\end{array}$ \\
\hline $\begin{array}{l}\text { Benedict et al, } \\
2009^{103}\end{array}$ & $\begin{array}{l}\text { MTLV, } \\
\text { DGMV }\end{array}$ & $\begin{array}{l}50 \mathrm{MS} \\
20 \text { controls }\end{array}$ & $\begin{array}{l}\text { DGM volumes correlated with neuropsychological measures; } \\
\text { amygdala volume correlated with episodic memory tests }\end{array}$ \\
\hline $\begin{array}{l}\text { Calabrese et al, } \\
2009^{53}\end{array}$ & NCV & $70 \mathrm{MS}$ & $\begin{array}{l}\text { Patients with cognitive impairment had more cortical } \\
\text { atrophy; NCV correlated with composite cognitive score }\end{array}$ \\
\hline $\begin{array}{l}\text { Audoin et al, } \\
2010^{97}\end{array}$ & $\begin{array}{l}\text { VBM } \\
\text { rGMV }\end{array}$ & $\begin{array}{l}62 \text { CIS, } \\
37 \text { controls }\end{array}$ & $\begin{array}{l}\text { Grey matter loss evident in various regions in CIS patients } \\
\text { compared with controls; right cerebellar atrophy correlated } \\
\text { with EDSS; no correlations with cognition }\end{array}$ \\
\hline $\begin{array}{l}\text { Roosendaal } \\
\text { et al, } 2011^{104}\end{array}$ & NGMV & $927 \mathrm{MS}$ & NGMV strongest predictor of EDSS and PASAT \\
\hline $\begin{array}{l}\text { Batista et al, } \\
2012^{105}\end{array}$ & $\begin{array}{l}\text { NCV, } \\
\text { DGMV }\end{array}$ & $86 \mathrm{MS}, 25 \mathrm{HC}$ & $\begin{array}{l}\text { Cortical and deep grey matter volumes correlated with } \\
\text { neuropsychological function }\end{array}$ \\
\hline \multicolumn{4}{|c|}{ 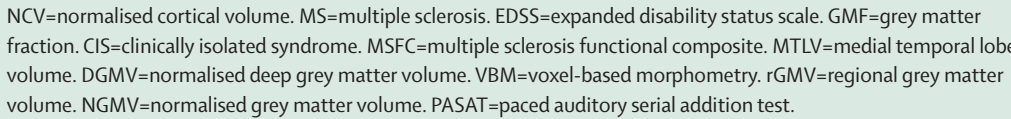 } \\
\hline
\end{tabular}




\begin{tabular}{|c|c|c|c|c|}
\hline & Measure & $\begin{array}{l}\text { Duration } \\
\text { (years) }\end{array}$ & $\mathrm{N}$ & Main findings \\
\hline $\begin{array}{l}\text { Chen et al, } \\
2004^{106}\end{array}$ & $\begin{array}{l}\text { Cortical } \\
\text { thinning }\end{array}$ & 1 & $30 \mathrm{MS}$ & $\begin{array}{l}-3.13 \% \text { change with worse disability; } 0.06 \% \text { change for } \\
\text { stable patients, } p<0.01\end{array}$ \\
\hline $\begin{array}{l}\text { Dalton et al, } \\
2004^{90}\end{array}$ & $\begin{array}{l}\text { GMF } \\
\text { change }\end{array}$ & 3 & $58 \mathrm{MS}$ & $\begin{array}{l}-3.3 \% \text { change in } \mathrm{CIS} \text { progressing to } \mathrm{MS} ;-1.1 \% \text { change in } \\
\text { CIS without } \mathrm{MS}, \mathrm{p}=0.02\end{array}$ \\
\hline $\begin{array}{l}\text { Amato et al, } \\
2007^{67}\end{array}$ & $\begin{array}{l}\text { NCV } \\
\text { change }\end{array}$ & $2 \cdot 5$ & $28 \mathrm{MS}$ & $\begin{array}{l}-43.0 \mathrm{~mL} \text { change with cognitive decline; }-17.8 \mathrm{~mL} \\
\text { change with stable cognition, } p<0.01\end{array}$ \\
\hline $\begin{array}{l}\text { Fisniku et al, } \\
2008^{102}\end{array}$ & $\begin{array}{l}\text { GMF at } \\
\text { follow-up }\end{array}$ & 20 & 73 MS & $\begin{array}{l}\text { Increase in grey matter atrophy in secondary progressive } \\
M S, p<0.01 ; \text { GMF correlated with EDSS or MSFC }\end{array}$ \\
\hline $\begin{array}{l}\text { Rudick et al, } \\
2009^{107}\end{array}$ & $\begin{array}{l}\text { GMF } \\
\text { change }\end{array}$ & 6.6 & $70 \mathrm{MS}$ & $\begin{array}{l}\text { Change in GMF } 14.2 \times \text { control rate with MSFC } \\
\text { worsening; change in GMF } 8.3 \times \text { control rate with MSFC } \\
\text { stable, } p=0.03\end{array}$ \\
\hline $\begin{array}{l}\text { Horakova et al, } \\
2009^{108}\end{array}$ & $\begin{array}{l}\text { NGMV } \\
\text { change }\end{array}$ & 5 & $181 \mathrm{MS}$ & $\begin{array}{l}\text { NGMV was a significant predictor of sustained EDSS } \\
\text { progression }\end{array}$ \\
\hline $\begin{array}{l}\text { Calabrese et al, } \\
2011^{98}\end{array}$ & $\begin{array}{l}\text { Cortical } \\
\text { thinning }\end{array}$ & 4 & $105 \mathrm{MS}$ & $\begin{array}{l}\text { Regional thinning in CIS progressing to relapsing- } \\
\text { remitting MS, } p<0.05 \text {; cortical thinning doubled risk of } \\
\text { conversion }\end{array}$ \\
\hline $\begin{array}{l}\text { Fisher et al, } \\
2011^{109}\end{array}$ & $\begin{array}{l}\text { Cortical } \\
\text { thinning }\end{array}$ & 4 & $70 \mathrm{MS}$ & $\begin{array}{l}\text { Lower baseline cortical thickness and more thinning in } \\
\text { patients with MSFC progression }\end{array}$ \\
\hline
\end{tabular}

$M S=$ multiple sclerosis. GMF=grey matter fraction. $\mathrm{CIS}=$ clinically isolated syndrome. $\mathrm{NCV}=$ normalised cortical volume. $E D S S=$ expanded disability status scale. $M S F C=$ multiple sclerosis functional composite. $N G M V=$ normalised grey matter volume.

Table 3: Longitudinal studies of grey matter atrophy and disability correlation

\begin{tabular}{|c|c|c|c|c|}
\hline & $\mathbf{N}$ & $\begin{array}{l}\text { Duration } \\
\text { (years) }\end{array}$ & Trial design & Results \\
\hline $\begin{array}{l}\text { Zivadinov } \\
\text { et al, } 2007^{110}\end{array}$ & 54 & 3 & $\begin{array}{l}\text { Non-randomised; intramuscular } \\
\text { interferon beta-1a vs untreated }\end{array}$ & $\begin{array}{l}\text { Decreased grey matter atrophy } \\
\text { with interferon beta }\end{array}$ \\
\hline $\begin{array}{l}\text { Nakamura } \\
\text { et al, } 2010^{111}\end{array}$ & 131 & 2 & $\begin{array}{l}\text { Randomised; intramuscular } \\
\text { interferon beta-1a vs placebo }\end{array}$ & $\begin{array}{l}\text { Decreased grey matter atrophy with } \\
\text { interferon beta; pseudoatrophy } \\
\text { mainly in white matter }\end{array}$ \\
\hline $\begin{array}{l}\text { Bendfeldt } \\
\text { et al, } 2010^{112}\end{array}$ & 86 & 2 & $\begin{array}{l}\text { Non-randomised; interferon beta- } \\
\text { 1a subcutaneous vs intramuscular } \\
\text { vs glatiramer acetate vs untreated }\end{array}$ & $\begin{array}{l}\text { Differences in regional grey matter } \\
\text { atrophy in (differentially) treated vs } \\
\text { non-treated patients with } \\
\text { relapsing-remitting multiple } \\
\text { sclerosis }\end{array}$ \\
\hline $\begin{array}{l}\text { Kapoor et al, } \\
2010^{113}\end{array}$ & 120 & 2 & $\begin{array}{l}\text { Randomised; lamotrigine vs } \\
\text { placebo }\end{array}$ & $\begin{array}{l}\text { Suggestion of white matter } \\
\text { pseudoatrophy; no effect on grey } \\
\text { matter atrophy }\end{array}$ \\
\hline $\begin{array}{l}\text { Calabrese et } \\
\text { al, } 2012^{114}\end{array}$ & 165 & 2 & $\begin{array}{l}\text { Randomised; interferon beta-1a } \\
\text { subcutaneous vs interferon beta-1a } \\
\text { intramuscular vs glatiramer acetate }\end{array}$ & $\begin{array}{l}\text { Cortical thinning comparable } \\
\text { between treatment groups }\end{array}$ \\
\hline
\end{tabular}

Various image analysis approaches have also been used to measure tissue loss in specific grey matter structures. Voxel-based morphometry provides a way to identify regions of the brain with substantial atrophic changes. For more specific analyses, deep grey matter structures can be isolated automatically and quantified accurately. ${ }^{82}$ Even sub-regions of the hippocampus can be identified and measured with a relatively high degree of reliability. ${ }^{89}$ The smaller the structure of interest, however, the more important it is to acquire high-resolution, high-contrast images, which might need more specialised MRI acquisition sequences than those used routinely in multiple sclerosis studies.

\section{Clinical relevance of grey matter atrophy}

Grey matter atrophy is relevant to the understanding of multiple sclerosis disability and to the design of clinical trials. Grey matter atrophy (but not white matter atrophy) can be detected in very early relapse-onset multiple sclerosis $\mathrm{s}^{90,91}$ and in early primary progressive multiple sclerosis. ${ }^{92,93}$ Unlike white matter atrophy, it can accelerate in the progressive (especially secondary progressive) disease stage (defined as continued deterioration for at least 6 months, with or without superimposed relapses in a patient with a history of at least two relapses). ${ }^{76}$ With a wide range of techniques, grey matter atrophy is evident even at the earliest stage of disease compared with healthy controls. ${ }^{91,94-98}$ In patients with clinically isolated syndromes, grey matter atrophy in specific regions (the superior frontal gyrus, thalamus, and cerebellum) independently predicted conversion to definite multiple sclerosis over 4 years, ${ }^{98}$ suggesting that grey matter atrophy might have a role in diagnosis. Several cross-sectional studies have shown significant correlations between various measures of grey matter atrophy and clinical disability, however disability was measured (table 2)..$^{53,95,97,99-105}$ In studies that analysed several MRI parameters, including T2 and T1 lesion volumes and white matter atrophy, grey matter atrophy was the strongest MRI correlate of clinical disability or cognitive impairment. ${ }^{95,100,101,104}$

Several longitudinal studies have assessed the relation between grey matter atrophy and clinical disability (table 3). ${ }^{67,90,98,102,106-109}$ Each of these reported significant correlations between continuing grey matter atrophy and concurrent disability progression. In one of the first reports about longitudinal grey matter atrophy in multiple sclerosis, ${ }^{106}$ cortical thinning was more prominent in patients with disability progression during the 1-year study than in those who remained stable. As shown in cross-sectional studies, progressive grey matter atrophy is more clinically relevant than white matter atrophy or lesions..$^{102,106,108}$ In a group of patients 20 years after their first attack, the grey matter fraction was the strongest predictor of disability, whereas the white matter fraction did not correlate with disability. ${ }^{102}$

\section{Grey matter atrophy in clinical trials}

Whether grey matter atrophy can be used as an outcome in neuroprotective treatment trials is not yet known, but publications reporting the effects of therapeutic interventions on grey matter atrophy are beginning to emerge (table 4). ${ }^{110-114}$ The authors of an open-label study of interferon beta-1a in relapsing-remitting multiple sclerosis suggested grey matter atrophy was decreased in treated compared with untreated patients. ${ }^{110}$ This result was confirmed in a post-hoc analysis of the randomised, placebo-controlled phase 3 clinical trial that led to approval of intramuscular interferon beta-1a. ${ }^{111}$ This study is of particular interest because the results suggested that pseudoatrophy - an increase in volume loss in the first 
year of anti-inflammatory therapy, thought to be due to resolution of oedema-was largely restricted to white matter. This fact has an important implication for the design of clinical trials using grey matter atrophy as an outcome measure because it implies that a run-in period to establish a stable baseline might not be necessary. In a placebo-controlled study of lamotrigine, ${ }^{113}$ although there were no treatment effects on grey matter atrophy, the reported volume changes were consistent with the idea that pseudoatrophy might be more prominent in white matter.

Because grey matter atrophy correlates with clinical disability more strongly than other MRI measures, and because it appears to be less sensitive to pseudoatrophy, grey matter atrophy could be an attractive potential outcome measure for neuroprotection trials.

\section{Conclusions and future directions}

Post-mortem tissue research has shown that the grey matter is very much involved in the multiple sclerosis disease process. During the past decade, this fundamental observation was followed by many studies aiming to investigate the clinical effects of grey matter damage. Recent research suggests that grey matter abnormalities can explain physical and cognitive decline in patients with multiple sclerosis better than white matter abnormalities can. Although an association between grey matter lesions and grey matter atrophy has been seen in multiple sclerosis, the two features are partially dissociated $^{54}$ and probably reflect different but interrelated pathological processes. Inflammatory demyelination characterises some grey matter lesions and might appear as the first phase of a process that can lead to atrophy. By contrast, grey matter atrophy seems to be the final step of several processes, which could include cortical demyelination but also retrograde degeneration secondary to white matter lesions, and, perhaps, primary neurodegeneration. Therefore, ideally, both focal lesions and diffuse atrophy should be assessed to better elucidate the pathological process underlying multiple sclerosis and to precisely predict the physical and cognitive evolution of the disease.

Measurement of grey matter damage in vivo remains a challenge: standard MRI techniques cannot adequately image grey matter lesions, and even more advanced techniques, such as double inversion recovery, are not sufficient to detect the majority of multiple sclerosis cortical lesions in vivo. Measurement of grey matter atrophy in multiple sclerosis is easier and more reproducible between sites than is the case for cortical lesions..$^{70}$ Future progress in understanding of the role of grey matter pathology in the disease process, and measurement of grey matter pathology for care of patients and clinical research, will need better methods to assess the disease process.

Despite the relevance of the results obtained so far, many important questions remain unresolved (panel).
Panel: Unresolved questions about grey matter pathology in multiple sclerosis

- What is the exact relation between grey matter pathology and white matter lesions?

- Does the disease start in the grey matter and involve white matter secondarily?

- Does white matter pathology involve grey matter secondarily?

- Does the multiple sclerosis pathological process independently target grey and white matter?

- What is the exact relation between grey matter lesions and grey matter atrophy?

- What pathological process explains type 3 cortical lesions?

- Are the pathological mechanisms for type 3 lesions fundamentally different from those for perivascular lesions in grey or white matter?

- What is the role of grey matter measurement in clinical trials?

- Can measurement of grey matter atrophy or lesions offer an advantage over whole brain or white matter assessments in pharmaceutical studies?

\section{Search strategy and selection criteria}

References for this Review were identified through searches of PubMed with the search terms "grey matter", "gray matter", "cortical", "GM atrophy", "GM lesions", "deep GM", "clinical AND multiple sclerosis AND GM atrophy", "clinical AND multiple sclerosis AND GM lesions", GM lesions AND histopathology", "GM lesions AND multiple sclerosis AND cognitive", "GM atrophy AND cognitive AND multiple sclerosis", "GM AND WM AND clinical AND multiple sclerosis", "treatment AND multiple sclerosis AND GM atrophy", "treatment AND multiple sclerosis AND GM lesions", "double inversion recovery AND multiple sclerosis AND GM lesions", "demyelination AND GM AND multiple sclerosis", "axonal AND multiple sclerosis AND histopathology", "neurodegeneration AND multiple sclerosis", "glutamate AND multiple sclerosis", "mitochondrial AND multiple sclerosis AND GM", "pathogenesis AND multiple sclerosis AND GM", from January, 1907 until July, 2012. We also identified articles through searches of the reference lists of the articles found with the above cited search terms and of the authors' own files. We reviewed only papers published in English. We generated the final reference list on the basis of originality and relevance to the scope of this Review.

Grey matter pathology, although it has been almost completely ignored until quite recently, holds many important secrets about the multiple sclerosis disease process. The implications of this fact range from improved diagnosis, monitoring of individual patients, improved understanding of disease pathogenesis and development, to a wider therapeutic window. Focused post-mortem studies and pathology-specific imaging measures should shed light on these important and intriguing questions in the future.

\section{Contributors}

JJGG and RAR prepared and designed the Review. All authors undertook the literature review, and MC and EF wrote the parts of the Review on in-vivo imaging and clinical relevance of grey matter lesions and atrophy, respectively. All the authors helped to revise the paper and agree with its final form.

\section{Conflicts of interest}

In the past 3 years, RAR has accepted honoraria or consulting fees from Biogen Idec, Wyeth/Pfizer, Genzyme, and Novartis. EF has received research support from Biogen Idec, Genzyme, and Pfizer/ Wyeth. She has also received personal compensation in the form of consulting fees, speaking honoraria, or both, from Biogen Idec, Genzyme, Novartis, and Teva. MC has no conflicts of interest to declare. JJGG has acted as a consultant for Merck Serono, Biogen Idec, and Teva in the same period. He has received personal compensation for consulting activities, and part of his research is 
supported by Biogen Idec and Merck Serono. None of the activities listed have been of influence to this Review.

\section{Acknowledgments}

The MS Center Amsterdam is sponsored by a research programme grant (09-358c). The work was also sponsored by grant NIH 2P50NS038667-11 (project 3: Gray Matter Atrophy in Multiple Sclerosis, PI Elizabeth Fisher, PhD)

References

1 Schob F. Ein beitrag zur patologischen anatomie der multiplen sklerose. Monatschrift Psychiatrie Neurol 1907; 22: 62-87.

2 Dawson JW. The histology of multiple sclerosis. Trans R Soc Edinburgh 1916; 50: 517-740.

3 Brownell B, Hughes JT. The distribution of plaques in the cerebrum in multiple sclerosis. J Neurol Neurosurg Psychiatry 1962; 25: 315-20.

4 Kutzelnigg A, Lucchinetti CF, Stadelmann C, et al. Cortical demyelination and diffuse white matter injury in multiple sclerosis. Brain 2005; 128: 2705-12.

5 Bo L, Vedeler CA, Nyland HI, Trapp BD, Mork SJ. Subpial demyelination in the cerebral cortex of multiple sclerosis patients. J Neuropathol Exp Neurol 2003; 62: 723-32.

6 Bo L, Vedeler CA, Nyland H, Trapp BD, Mork SJ. Intracortica multiple sclerosis lesions are not associated with increased lymphocyte infiltration. Mult Scler 2003; 9: 323-31.

7 Geurts JJ, Barkhof F. Grey matter pathology in multiple sclerosis. Lancet Neurol 2008; 7: 841-51.

8 Hulst HE, Geurts JJ. Gray matter imaging in multiple sclerosis: what have we learned? BMC Neurol 2011; 11: 153-63.

9 Lublin FD, Reingold SC. Defining the clinical course of multiple sclerosis: results of an international survey. National Multiple Sclerosis Society (USA) Advisory Committee on Clinical Trials of New Agents in Multiple Sclerosis. Neurology 1996; 46: 907-11.

10 Gilmore CP, Donaldson I, Bo L, et al. Regional variations in the extent and pattern of grey matter demyelination in multiple sclerosis: a comparison between the cerebral cortex, cerebellar cortex, deep grey matter nuclei and the spinal cord. J Neurol Neurosurg Psychiatry 2009; 80: 182-87.

11 Vercellino M, Plano F, Votta B, et al. Grey matter pathology in multiple sclerosis. J Neuropathol Exp Neurol 2005; 64: 1101-07.

12 Kutzelnigg A, Faber-Rod JC, Bauer J, et al. Widespread demyelination in the cerebellar cortex in multiple sclerosis. Brain Pathol 2007; 17: 38-44.

13 Geurts JJ, Bo L, Roosendaal SD, et al. Extensive hippocampal demyelination in multiple sclerosis. J Neuropathol Exp Neurol 2007; 66: 819-27.

14 Huitinga I, De Groot CJ, van der Valk P, et al. Hypothalamic lesions in multiple sclerosis. J Neuropathol Exp Neurol 2001; 60: 1208-18.

15 Gilmore CP, Bo L, Owens T, et al. Spinal cord gray matter demyelination in multiple sclerosis-a novel pattern of residual plaque morphology. Brain Pathol 2006; 16: 202-08.

16 Papadopoulos D, Dukes S, Patel R, et al. Substantial archaeocortical atrophy and neuronal loss in multiple sclerosis. Brain Pathol 2009; 19: 238-53.

17 Dutta R, Chang A, Doud MK, et al. Demyelination causes synaptic alterations in hippocampi from multiple sclerosis patients. Ann Neurol 2011; 69: 445-54.

18 Benedict RH, Fischer JS, Archibald CJ, et al. Minimal neuropsychological assessment of MS patients: a consensus approach. Clin Neuropsychol 2002; 16: 381-97.

19 Peterson JW, Bo L, Mork S, Chang A, Trapp BD. Transected neurites, apoptotic neurons, and reduced inflammation in cortical multiple sclerosis lesions. Ann Neurol 2001; 50: 389-400.

20 Bo L, Geurts JJ, van der Valk P, Polman C, Barkhof F. Lack of correlation between cortical demyelination and white matter pathologic changes in multiple sclerosis. Arch Neurol 2007; 64: 76-80.

21 Wegner C, Esiri MM, Chance SA, Palace J, Matthews PM. Neocortical neuronal, synaptic, and glial loss in multiple sclerosis. Neurology 2006; 67: 960-67.

22 Kooi EJ, Prins M, Bajic N, et al. Cholinergic imbalance in the multiple sclerosis hippocampus. Acta Neuropathol 2011; 122: 313-22.

23 Magliozzi R, Howell O, Vora A, et al. Meningeal B-cell follicles in secondary progressive multiple sclerosis associate with early onset of disease and severe cortical pathology. Brain 2007; 130: 1089-104.
24 Howell OW, Reeves CA, Nicholas R, et al. Meningeal inflammation is widespread and linked to cortical pathology in multiple sclerosis. Brain 2011; 134: 2755-71.

25 Kooi EJ, Geurts JJ, van Horssen J, Bo L, van der Valk P. Meningeal inflammation is not associated with cortical demyelination in chronic multiple sclerosis. J Neuropathol Exp Neurol 2009; 68: 1021-28.

26 Serafini B, Rosicarelli B, Franciotta D, et al. Dysregulated Epstein-Barr virus infection in the multiple sclerosis brain J Exp Med 2007; 204: 2899-912.

27 Torkildsen O, Stansberg C, Angelskar SM, et al. Upregulation of immunoglobulin-related genes in cortical sections from multiple sclerosis patients. Brain Pathol 2010; 20: 720-29.

28 Willis SN, Stadelmann C, Rodig SJ, et al. Epstein-Barr virus infection is not a characteristic feature of multiple sclerosis brain. Brain 2009; 132: 3318-28.

29 Lassmann H, Niedobitek G, Aloisi F, Middeldorp JM. Epstein-Barr virus in the multiple sclerosis brain: a controversial issue-report on a focused workshop held in the Centre for Brain Research of the Medical University of Vienna, Austria. Brain 2011; 134: 2772-86.

30 Brink BP, Veerhuis R, Breij EC, et al. The pathology of multiple sclerosis is location-dependent: no significant complement activation is detected in purely cortical lesions. J Neuropathol Exp Neurol 2005; 64: 147-55.

31 van Horssen J, Brink BP, de Vries HE, van der Valk P, Bo L. The blood-brain barrier in cortical multiple sclerosis lesions. J Neuropathol Exp Neurol 2007; 66: 321-28.

32 Lucchinetti CF, Popescu BF, Bunyan RF, et al. Inflammatory cortical demyelination in early multiple sclerosis. N Engl J Med 2011; 365: 2188-97.

33 Popescu BF, Bunyan RF, Parisi JE, Ransohoff RM, Lucchinetti CF. A case of multiple sclerosis presenting with inflammatory cortical demyelination. Neurology 2011; 76: 1705-10.

34 Campbell GR, Ziabreva I, Reeve AK, et al. Mitochondrial DNA deletions and neurodegeneration in multiple sclerosis. Ann Neurol 2011; 69: 481-92.

35 Vercellino M, Merola A, Piacentino C, et al. Altered glutamate reuptake in relapsing-remitting and secondary progressive multiple sclerosis cortex: correlation with microglia infiltration, demyelination, and neuronal and synaptic damage. J Neuropathol Exp Neurol 2007; 66: 732-39.

36 Srivastava R, Aslam M, Kalluri SR, et al. Potassium channel KIR4.1 as an immune target in multiple sclerosis. N Engl J Med 2012; 367: 115-23.

37 Trapp BD, Stys PK. Virtual hypoxia and chronic necrosis of demyelinated axons in multiple sclerosis. Lancet Neurol 2009; 8: $280-91$.

38 Geurts JJ, Stys PK, Minagar A, Amor S, Zivadinov R. Gray matter pathology in (chronic) MS: modern views on an early observation. J Neurol Sci 2009; 282: 12-20.

39 Stys PK, Zamponi GW, van Minnen J, Geurts JJ. Will the real multiple sclerosis please stand up? Nat Rev Neurosci 2012; 13: 507-14.

40 Geurts JJ, Roosendaal SD, Calabrese M, et al. Consensus recommendations for MS cortical lesion scoring using double inversion recovery MRI. Neurology 2011; 76: 418-24.

41 Turetschek K, Wunderbaldinger P, Bankier AA, et al. Double inversion recovery imaging of the brain: initial experience and comparison with fluid attenuated inversion recovery imaging. Magn Reson Imaging 1998; 16: 127-35.

42 Geurts JI, Pouwels PJ, Uitdehaag BM, et al. Intracortical lesions in multiple sclerosis: improved detection with 3D double inversionrecovery MR imaging. Radiology 2005; 236: 254-60.

43 Seewann A, Kooi EJ, Roosendaal SD, et al. Post mortem verification of MS cortical lesion detection with 3D-DIR. Neurology 2012; 78: 302-08.

44 Geurts JJ, Blezer EL, Vrenken H, et al. Does high-field MR imaging improve cortical lesion detection in multiple sclerosis? J Neurol 2008; 255: 183-91.

45 Seewann A, Vrenken H, Kooi EJ, et al. Imaging the tip of the iceberg: visualization of cortical lesions in multiple sclerosis. Mult Scler 2011; 17: 1202-10.

46 Nelson F, Poonawalla AH, Hou P, et al. Improved identification of intracortical lesions in multiple sclerosis with phase-sensitive inversion recovery in combination with fast double inversion recovery MR imaging. AJNR Am J Neuroradiol 2007; 28: 1645-49. 
47 Bagnato F, Butman JA, Gupta S, et al. In vivo detection of cortical plaques by MR imaging in patients with multiple sclerosis. AJNR Am J Neuroradiol 2006; 27: 2161-67.

48 Mainero C, Benner T, Radding A, et al. In vivo imaging of cortical pathology in multiple sclerosis using ultra-high field MRI. Neurology 2009; 73: 941-48.

49 Schmierer K, Parkes HG, So PW, et al. High field (9.4 Tesla) magnetic resonance imaging of cortical grey matter lesions in multiple sclerosis. Brain 2010; 133: 858-67.

50 Calabrese M, De Stefano N, Atzori M, et al. Detection of cortical inflammatory lesions by double inversion recovery magnetic resonance imaging in patients with multiple sclerosis. Arch Neurol 2007; 64: 1416-22.

51 Calabrese M, Filippi M, Rovaris M, et al. Evidence for relative cortical sparing in benign multiple sclerosis: a longitudinal magnetic resonance imaging study. Mult Scler 2009; 15: 36-41.

52 Roosendaal SD, Moraal B, Pouwels P, et al. Accumulation of cortical lesions in MS: relation with cognitive impairment. Mult Scler 2009; 15: 708-14.

53 Calabrese M, Agosta F, Rinaldi F, et al. Cortical lesions and atrophy associated with cognitive impairment in relapsing-remitting multiple sclerosis. Arch Neurol 2009; 66: 1144-50.

54 Calabrese M, Rocca MA, Atzori M, et al. Cortical lesions in primary progressive multiple sclerosis: a 2-year longitudinal MR study. Neurology 2009; 72: 1330-36.

55 Calabrese M, Rocca MA, Atzori M, et al. A 3-year magnetic resonance imaging study of cortical lesions in relapse-onset multiple sclerosis. Ann Neurol 2010; 67: 376-83.

56 Bagnato F, Salman Z, Kane R, et al. T1 cortical hypointensities and their association with cognitive disability in multiple sclerosis. Mult Scler 2010; 16: 1203-12.

57 Mike A, Glanz BI, Hildenbrand P, et al. Identification and clinical impact of multiple sclerosis cortical lesions as assessed by routine 3T MR imaging. AJNR Am J Neuroradiol 2011; 32: 515-21.

58 Nelson F, Datta S, Garcia N, et al. Intracortical lesions by 3T magnetic resonance imaging and correlation with cognitive impairment in multiple sclerosis. Mult Scler 2011; 17: 1122-29.

59 Nielsen AS, Kinkel RP, Tinelli E, et al. Focal cortical lesion detection in multiple sclerosis: 3 tesla DIR versus 7 tesla FLASH-T2*. J Magn Reson Imaging 2011; 35: 537-42.

60 Giorgio A, Stromillo ML, Rossi F, et al. Cortical lesions in radiologically isolated syndrome. Neurology 2011; 77: 1896-99.

61 Calabrese M, Gallo P. Magnetic resonance evidence of cortical onset of multiple sclerosis. Mult Scler 2009; 15: 933-41.

62 Coebergh JA, Roosendaal SD, Polman CH, Geurts JJ, van Woerkom TC. Acute severe memory impairment as a presenting symptom of multiple sclerosis: a clinical case study with 3D double inversion recovery MR imaging. Mult Scler 2010; 16: 1521-24.

63 Filippi M, Rocca MA, Calabrese M, et al. Intracortical lesions: relevance for new MRI diagnostic criteria for multiple sclerosis. Neurology 2010; 75: 1988-94.

64 Swanton JK, Rovira A, Tintore M, et al. MRI criteria for multiple sclerosis in patients presenting with clinically isolated syndromes: a multicentre retrospective study. Lancet Neurol 2007; 6: 677-86.

65 Polman CH, Reingold SC, Banwell B, et al. Diagnostic criteria for multiple sclerosis: 2010 revisions to the McDonald criteria. Ann Neurol 2011; 69: 292-302.

66 Thompson AJ, Montalban X, Barkhof F, et al. Diagnostic criteria for primary progressive multiple sclerosis: a position paper. Ann Neurol 2000; 47: 831-35.

67 Amato MP, Portaccio E, Goretti B, et al. Association of neocortical volume changes with cognitive deterioration in relapsing-remitting multiple sclerosis. Arch Neurol 2007; 64: 1157-61.

68 Amato MP, Zipoli V, Portaccio E. Multiple sclerosis-related cognitive changes: a review of cross-sectional and longitudinal studies. J Neurol Sci 2006; 245: 41-46.

69 Roosendaal SD, Moraal B, Vrenken H, et al. In vivo MR imaging of hippocampal lesions in multiple sclerosis. J Magn Reson Imaging 2006; 27: 726-31.

70 Barkhof F, Calabresi PA, Miller DH, Reingold SC. Imaging outcomes for neuroprotection and repair in multiple sclerosis trials. Nat Rev Neurol 2009; 5: 256-66.
71 Miller DH, Barkhof F, Frank JA, Parker GJ, Thompson AJ. Measurement of atrophy in multiple sclerosis: pathological basis, methodological aspects and clinical relevance. Brain 2002; 125: 1676-95.

72 Simon JH. Brain atrophy in multiple sclerosis: what we know and would like to know. Mult Scler 2006; 12: 679-87.

73 Giorgio A, Battaglini M, Smith SM, De SN. Brain atrophy assessment in multiple sclerosis: importance and limitations. Neuroimaging Clin N Am 2008; 18: 675-86, xi.

74 Fisher E. Measurement of CNS atrophy. In: Cohen JA, Rudick R, eds. Multiple sclerosis therapeutics, 4th edn. Cambridge, UK: Cambridge University Press, 2011.

75 Bakshi R, Dandamudi VS, Neema M, De C, Bermel RA. Measurement of brain and spinal cord atrophy by magnetic resonance imaging as a tool to monitor multiple sclerosis. J Neuroimaging 2005; 15: 30S-45S.

76 Fisher E, Lee JC, Nakamura K, Rudick RA. Gray matter atrophy in multiple sclerosis: a longitudinal study. Ann Neurol 2008; 64: 255-65.

77 Ashburner J, Friston K. Multimodal image coregistration and partitioning-a unified framework. Neuroimage 1997; 6: 209-17.

78 Ashburner J, Friston KJ. Voxel-based morphometry-the methods. Neuroimage 2000; 11: 805-21.

79 Nakamura K, Fisher E. Segmentation of brain magnetic resonance images for measurement of gray matter atrophy in multiple sclerosis patients. Neuroimage 2009; 44: 769-76.

80 Smith SM, De SN, Jenkinson M, Matthews PM. Normalized accurate measurement of longitudinal brain change. J Comput Assist Tomogr 2001; 25: 466-75.

81 Smith SM, Zhang Y, Jenkinson M, et al. Accurate, robust, and automated longitudinal and cross-sectional brain change analysis. Neuroimage 2002; 17: 479-89.

82 Patenaude B, Smith SM, Kennedy DN, Jenkinson M. A Bayesian model of shape and appearance for subcortical brain segmentation. Neuroimage 2011; 56: 907-22.

83 Zeineh MM, Engel SA, Thompson PM, Bookheimer SY. Unfolding the human hippocampus with high resolution structural and functional MRI. Anat Rec 2001; 265: 111-20.

84 Derakhshan M, Caramanos Z, Giacomini PS, et al. Evaluation of automated techniques for the quantification of grey matter atrophy in patients with multiple sclerosis. Neuroimage 2010; 52: 1261-67.

85 FSL_Fsl Wiki. http://fsl.fmrib.ox.ac.uk/fsl/fslwiki/. September, 2012 (accessed 25 Sept, 2012).

86 Chard DT, Parker GJ, Griffin CM, Thompson AJ, Miller DH. The reproducibility and sensitivity of brain tissue volume measurements derived from an SPM-based segmentation methodology. J Magn Reson Imaging 2002; 15: 259-67.

87 Fischl B, Dale AM. Measuring the thickness of the human cerebral cortex from magnetic resonance images. Proc Natl Acad Sci USA 2000; 97: 11050-55.

88 Nakamura K, Fox R, Fisher E. CLADA: cortical longitudinal atrophy detection algorithm. Neuroimage 2011; 54: 278-89.

89 Sicotte NL, Kern KC, Giesser BS, et al. Regional hippocampal atrophy in multiple sclerosis. Brain 2008; 131: 1134-41.

90 Dalton CM, Chard DT, Davies GR, et al. Early development of multiple sclerosis is associated with progressive grey matter atrophy in patients presenting with clinically isolated syndromes. Brain 2004; 127: 1101-07.

91 Tiberio M, Chard DT, Altmann DR, et al. Gray and white matter volume changes in early RRMS: a 2-year longitudinal study. Neurology 2005; 64: 1001-07.

92 Sastre-Garriga J, Ingle GT, Chard DT, et al. Grey and white matter volume changes in early primary progressive multiple sclerosis: a longitudinal study. Brain 2005; 128: 1454-60.

93 Sepulcre J, Sastre-Garriga J, Cercignani M, et al. Regional gray matter atrophy in early primary progressive multiple sclerosis: a voxel-based morphometry study. Arch Neurol 2006; 63: 1175-80.

94 Chard DT, Griffin CM, Parker GJ, Kapoor R, Thomson AJ, Miller DH. Brain atrophy in clinically early relapsing-remitting multiple sclerosis. Brain 2002; 125: 327-37.

95 De Stefano N, Matthews PM, Filippi M, et al. Evidence of early cortical atrophy in MS: relevance to white matter changes and disability. Neurology 2003; 60: 1157-62. 
96 Henry RG, Shieh M, Okuda DT, et al. Regional grey matter atrophy in clinically isolated syndromes at presentation.

J Neurol Neurosurg Psychiatry 2008; 79: 1236-44.

97 Audoin B, Zaaraoui W, Reuter F, et al. Atrophy mainly affects the limbic system and the deep grey matter at the first stage of multiple sclerosis. J Neurol Neurosurg Psychiatry 2010; 81: 690-95.

98 Calabrese M, Rinaldi F, Mattisi I, et al. The predictive value of gray matter atrophy in clinically isolated syndromes. Neurology 2011; 77: 257-63.

99 Amato MP, Bartolozzi ML, Zipoli V, et al. Neocortical volume decrease in relapsing-remitting MS patients with mild cognitive impairment. Neurology 2004; 63: 89-93.

100 Tedeschi G, Lavorgna L, Russo P, et al. Brain atrophy and lesion load in a large population of patients with multiple sclerosis. Neurology 2005; 65: 280-85.

101 Sanfilipo MP, Benedict RH, Sharma J, Weinstock-Guttman B, Bakshi R. The relationship between whole brain volume and disability in multiple sclerosis: a comparison of normalized gray vs. white matter with misclassification correction. Neuroimage 2005; 26: 1068-77.

102 Fisniku LK, Chard DT, Jackson JS, et al. Gray matter atrophy is related to long-term disability in multiple sclerosis. Ann Neurol 2008; 64: 247-54.

103 Benedict RH, Ramasamy D, Munschauer F, Weinstock-Guttman B, Zivadinov R. Memory impairment in multiple sclerosis: correlation with deep grey matter and mesial temporal atrophy. J Neurol Neurosurg Psychiatry 2009; 80: 201-06.

104 Roosendaal SD, Bendfeldt K, Vrenken H, et al. Grey matter volume in a large cohort of MS patients: relation to MRI parameters and disability. Mult Scler 2011; 17: 1098-106.

105 Batista S, Zivadinov R, Hoogs M, et al. Basal ganglia, thalamus and neocortical atrophy predicting slowed cognitive processing in multiple sclerosis. J Neurol 2012; 259: 139-46.
106 Chen JT, Narayanan S, Collins DL, et al. Relating neocortical pathology to disability progression in multiple sclerosis using MRI. Neuroimage 2004; 23: 1168-75.

107 Rudick RA, Lee JC, Nakamura K, Fisher E. Gray matter atrophy correlates with MS disability progression measured with MSFC but not EDSS. J Neurol Sci 2009; 282: 106-11.

108 Horakova D, Dwyer MG, Havrdova E, et al. Gray matter atrophy and disability progression in patients with early relapsing-remitting multiple sclerosis: a 5-year longitudinal study. J Neurol Sci 2009; 282: 112-19.

109 Fisher E, Nakamura K, Lee J-C, Rudick RA. Cortical thinning and disability progression in multiple sclerosis. Neurology 2011; 76 (suppl 4): A324 (abstr).

110 Zivadinov R, Locatelli L, Cookfair D, et al. Interferon beta-1a slows progression of brain atrophy in relapsing-remitting multiple sclerosis predominantly by reducing gray matter atrophy. Mult Scler 2007; 13: 490-501.

111 Nakamura K, Rudick R, Lee JC, Foulds P, Fisher E. Effect of intramuscular interferon beta-1a on gray matter atrophy in relapsing-remitting multiple sclerosis. Neurology 2010; 74: A407 (abstr).

112 Bendfeldt K, Egger H, Nichols TE, et al. Effect of immunomodulatory medication on regional gray matter loss in relapsing-remitting multiple sclerosis-a longitudinal MRI study. Brain Res 2010; 1325: 174-82.

113 Kapoor R, Furby J, Hayton T, et al. Lamotrigine for neuroprotection in secondary progressive multiple sclerosis: a randomised, double-blind, placebo-controlled, parallel-group trial. Lancet Neurol 2010; 9: 681-88.

114 Calabrese M, Bernardi V, Atzori M. Effect of disease-modifying drugs on cortical lesions and atrophy in relapsing-remitting multiple sclerosis. Mult Scler 2012; 18: 174-80. 